http://jmscr.igmpublication.org/home/

ISSN (e)-2347-176x ISSN (p) 2455-0450

crossref DOI: https://dx.doi.org/10.18535/jmscr/v9i7.29

Journal Of Medical Science And Clinical Research

IGM Publication

An Official Publication of IGM Publication

\title{
Profile of Substance Use Patients at State Mental Health Hospital
}

\author{
Authors \\ Abhilaksh Kango ${ }^{*}$, Anukriti Singh ${ }^{2}$ \\ ${ }^{1}$ Psychiatrist, Himachal Hospital of Mental Health and Rehabilitation, Shimla (HP) \\ ${ }^{2}$ Medical officer, IGMC, Shimla (HP) \\ *Corresponding Author \\ Dr Abhilaksh Kango
}

Psychiatrist, Himachal Hospital of Mental Health and Rehabilitation, Shimla (HP), 171005, India

\begin{abstract}
Aim: The aim of the study was to study the clinical and sociodemographic profile of substance use patients seeking treatment at State Mental Health Hospital.

Material and Methods: It was a cross - sectional observation conducted from February 2021 to March 2021. Seventy consecutive treatment-seeking patients for substance use providing informed consent were included in the study.
\end{abstract}

Results: 70 substance use patients attending OPD were included in study majority of which were males. Around 78\% participants had family history of substance use. Mean age of sample came out be 25.71 ( $S D \pm 4.16)$ years. Majority of patients started substance use between 21 to 30 years. Most common substance used was opioid (84.3\%) followed by tobacco (78.6\%). Peer pressure (44.3\%) has been reported as most common reason for initiation substance use.

Conclusion: It is suggestive that substance use is initiated in teenage which is most commonly due to peer pressure. So, young people are more vulnerable to get indulged in substance use and policies to prevent and address this should be in place precisely during teenage years.

Keywords: Himachal Hospital of Mental Health and Rehabilitation (HHMH\&R).

\section{Introduction}

Around $5 \%$ of total population of India is suffering from substance use disorders as reported in National Mental Health Survey (2015-2016) ${ }^{1}$. As per survey done in 2019 considerable number of people abuse psychoactive substances in our country, and it is prevalent among all subgroups of population ${ }^{2}$. During recent years opioid use has turned out to be most prevalent among various mental health disorders, but very few have studied substance use patients' profilein north India. In recent decade there is major changes in practices of drug abuse in Himachal Pradesh, there is rise in illicit opioid use via chasing as well as intravenous use along with stimulants and heavy cannabis use whereas earlier alcohol was main substance of abuse. Appropriate assessment of these trends of substance use, especially illicit drugs such as opioids and stimulants, has become important to control this upcoming crisis.

\section{Materials and Methods}

It was a cross sectional observation done at OPD facility of State Mental Health Hospital, Shimla. The duration of the study was from February 2021 to March 2021. Seventy treatment- seeking 
patients, Diagnosed according to the International Classification of Diseases version 10 were involved after informed consent. A semi- structured interview was done to elicit sociodemographic and clinical details of participants. Analysis of data collected was done by SPSS (Statistical Package for Social Sciences).

\section{Results}

All the participants were male and mean age was 25.71 ( $\mathrm{SD} \pm 4.16)$ years. Significant proportion of participants $(44 \%)$ were graduate and $47 \%$ were skilled professionals. Most of participants were single $(80 \%) \quad \& 78 \%$ had family history of substance use. Above information is provided in Table 1. In Table 2(A) it is evident that majority of participants $(55.7 \%)$ started substance use between 21-30 years of age. The duration of substance use was more than 24 months in around $63 \%$ of participants. Most of participants were poly-substance users in which illicit opioids were most common used substance $(84.3 \%)$ followed by tobacco $(78.6 \%)$. Reasons provided for initiation and continuing of substance use are provided in Table 2(B). $44.3 \%$ participants reported peer pressure as reason for initiating substance followed by curiosity (32.9\%). Experiencing withdrawal was most common reason $(41.4 \%)$ for continuing substance use followed by enjoyment and re-experiencing pleasurable effect $(27.1 \%)$. In reasons to visit our center difficulty in procuring substance was most common $(31 \%)$ followed by continuous craving and withdrawal (24.3\%).

Table 1:- Sociodemographic characteristics.

\begin{tabular}{|l|c|}
\hline Socio-demographic variables & $\begin{array}{c}\text { N=70 } \\
\text { Mean (SD)/ } \\
\text { Frequency (\%) }\end{array}$ \\
\hline Age (in years) & $25.71(4.16)$ \\
\hline Educational status & $13(18.6 \%)$ \\
High school & $26(37.1 \%)$ \\
Intermediate or post high school diploma & $31(44.3 \%)$ \\
\hline Graduate or Postgraduate & \\
\hline Occupational status & $09(12.9 \%)$ \\
Student & $18(25.7 \%)$ \\
Unemployed & $28(47.1 \%)$ \\
Skilled/Semi-skilled worker & $09(12.9 \%)$ \\
Clerical/Shop owner/Farmer & $06(8.6 \%)$ \\
Professional/Semi-professional & \\
\hline Marital Status & $56(80 \%)$ \\
Single & $14(21 \%)$ \\
Married & $65(78.5 \%)$ \\
\hline Substance use in family & $15(21.5 \%)$ \\
Yes & \\
No & \\
\hline
\end{tabular}

Table 2(A): - Substance use characteristics.

\begin{tabular}{|c|c|}
\hline Characteristics & $\begin{array}{c}\mathbf{N}=70 \\
\text { Mean (SD)/ } \\
\text { Frequency }(\%)\end{array}$ \\
\hline $\begin{array}{l}\text { Age at which initiated (yrs.) } \\
<=20 \\
21-30 \\
31-40\end{array}$ & $\begin{array}{c}28(40 \%) \\
39(55.7 \%) \\
03(4.2)\end{array}$ \\
\hline $\begin{array}{llll}\begin{array}{l}\text { Duration of } \\
\text { (months) }\end{array} & & & \\
<=6 & & & \\
6-12 & & & \\
12-24 & & & \\
>24 & & & \end{array}$ & $\begin{array}{c}03(4.3 \%) \\
09(12.9 \%) \\
14(20 \%) \\
44(62.9 \%)\end{array}$ \\
\hline $\begin{array}{l}\text { Type of substance used } \\
\text { Opioid } \\
\text { Alcohol } \\
\text { Cannabis } \\
\text { Tobacco }\end{array}$ & $\begin{array}{l}59(84.3 \%) \\
34(48.6 \%) \\
30(42.8 \%) \\
55(78.6 \%)\end{array}$ \\
\hline
\end{tabular}


Table 2(A): Substance use characteristics

\begin{tabular}{|l|c|}
\hline Characteristics & $\begin{array}{c}\text { N=70 } \\
\text { Mean (SD)/ } \\
\text { Frequency (\%) }\end{array}$ \\
\hline Reasons for initiating substance use \\
\hline Peer pressure & $31(44.3 \%)$ \\
\hline Curiosity & $23(32.9 \%)$ \\
\hline Family and work-related stress & $14(18.5 \%)$ \\
\hline Academic related stress & $03(4.3 \%)$ \\
\hline Reason for continuing substance use \\
\hline Enjoyment and re-experiencing & $19(27.1 \%)$ \\
\hline Experiencing withdrawal & $29(41.4 \%)$ \\
\hline Easy accessibility & $11(15.7 \%)$ \\
\hline Family or work-related stress & $11(15.7 \%)$ \\
\hline Reasons to visit our centre & \\
\hline Continuous craving and withdrawal & $17(24.3 \%)$ \\
\hline Problems in family or work & $12(17.1 \%)$ \\
\hline Difficulty in procuring & $22(31 \%)$ \\
\hline Medical issues & $09(12.9 \%)$ \\
\hline Made to visit by family members & $10(14.3 \%)$ \\
\hline
\end{tabular}

\section{Discussion}

As a developing country our country is encountering multiple epidemics at one end there are infectious diseases and life style related diseases on the other. Mental health issues including substance use are other challenges which has to be dealt with. Overall substance use starts at early age which is documented. Majority of participants in our study started substance use in age between 21 to 30 years which is in accordance with existing literature ${ }^{3-5}$.

Most participants were male which is consistent with literature $e^{6-8}$ in which it is seen that substance users are more likely to be male. The less females at the de-addiction facilities can be due to the stigma and embarrassment linked with substance use, kept aside the male predominance of male in substance use ${ }^{9}$.

In our study participants were predominantly graduate or post-graduate $(44.3 \%)$, followed by intermediate or post high school diploma (37.1\%), which are almost in accordance with existing literature $^{7,9}$. Most of the participants were single and majority have family history of mental illness ${ }^{7}$.

Most common used substance in our study was illicit opioids in various forms $(84.3 \%)$, followed by tobacco $(78.6 \%)$ which is consistent with existing literature ${ }^{3,7,9}$. The main reasons reported behind initiating substance use were peer pressure (44.3\%) followed by curiosity(32.9\%). Peer pressure has also been mentioned as a major initiating factor in previous studies too ${ }^{3,7}$.

Majority of substance users reported experiencing withdrawal $(41.4 \%)$ as most common reason for regular use followed by enjoyment and reexperiencing the effect $(27 \%)$. Majority reported difficulty in procuring substance $(31 \%)$ that continuous craving and withdrawal $(24.3 \%)$ as reasons to visit our facility. These are also in accordance with the literature ${ }^{10}$.

\section{Conclusions}

There are no major studies done in our state to reflect the prevalence of substance use and also no guideline-based steps are taken to combat the current situation. Our study highlights the overall change in pattern of substance use and also the burden which will help to design policies and protocols and emphasize on need for development of dedicated de-addiction centres at district levels to effectively deal with this epidemic and also encourage for further more methodologically robust studies at community level. 


\section{References}

1. National Mental Health Survey of India, 2015- 2016 Prevalence, Patterns and Outcomes, Supported by Ministry of Health and Family Welfare, Government of India, and Implemented by National institute of Mental Health and Neurosciences (NIMHANS). Bengaluru: In Collaboration with Partner Institutions; 2015- 2016.

2. Magnitude of Substance Use in India, 2019. National Survey on Extent and Pattern of Substance Use in India. New Delhi: Ministry of Social Justice and Empowerment, Government of India; 2019.

3. Din NU, Khan AW, Suhaff AA, Hussain Z, Ganai AM, Mir SA, et al. Socio- demographic \& clinical profile of patients with substance used is orders seeking treatment: A hospital based study. Res Med Eng Sci 2019;7:808- 14.

4. Roy S, Zubayer M. Socio- demographic and clinical profile of substance abusers attending a Regional Psychiatric Hospital in Sylhet, Bangladesh. J Addict Res Ther2017;8:342.

5. Khandhedia S, Raval CM, Thakor N. Profile of substance abusers attending at de- addiction center of GMERS Medical College, Dharpur- Patna, Gujarat, India: A cross sectional study. Int J Res Med Sci 2015;3:2765- 9.

6. Prajapati BB, Dedun MR, Jalfava $H$, Shukla A. A study of socio- demographic profile and pattern of drug use among substance abusers attending mind care de- addiction center in Ahmedabad. Int $\mathbf{J}$ Community Med Public Health 2019;6:286- 9.

7. Rather YH, Bashir W, Sheikh AA, Amin M, Zahgeer YA. Socio- demographic and clinical profile of substance abusers attending a regional drug de- addiction centre in chronic conflict area: Kashmir, India. Malays J Med Sci 2013;20:31- 8.

8. Arora H, Gupta S, Kajal KS, Padda P, Monga S, Devgan S, et al. Evaluation of socio- demographic profile of the drug abusers visiting drug deaddiction centre at Faridkot, Punjab. J Adv Med Dent Sci Res 2016;4:135- 41.

9. Gul D, Sharma N. Sociodemographic profile and pattern of substance abuse among patients presenting to a deaddiction centre in a teaching hospital of Punjab. Int J Med and Dent Sci 2017;6:1504- 8.

10. Kumar N, Kanchan T, Unnikrishnan B, Thapar R, Mithra P, Kulkarni V, et al. Profile of substance use among patients attending de- addiction centres in a coastal city of Southern India. PLoS One 2013;8:1- 4. 